\title{
Hybridization between oilseed rape (Brassica napus) and different populations and species of Raphanus
}

\author{
Henriette AMMITZBøLL and Rikke BAGGER JøRGENSEN* \\ Biosystems Department, Risø National Laboratory, P.O. Box 49, 4000 Roskilde, Denmark
}

\begin{abstract}
When cultivating genetically modified varieties, the spontaneous gene flow between crop and wild relatives could be of concern. We analyzed spontaneous hybridization between a transgenic male-sterile line of oilseed rape (Brassica napus, $2 n=38$, AACC) and, as pollen donors, three European populations of wild radish (Raphanus raphanistrum, $2 n=18, \mathrm{Rr}, \mathrm{Rr}$ ) and a variety of cultivated radish (Raphanus sativus, $2 n=18$, RR). Seeds showed size and shape dimorphism that correlated to the frequency of hybrids. The offspring were scored morphologically and analyzed using DNA markers (inter-simple sequence repeats) to quantify hybrid frequencies. Seed set ranged from 0.4-1.2 seeds per pod, and 0.02-0.6 seeds per pod were confirmed as hybrids. The frequency of confirmed hybrids differed significantly among populations of $R$. raphanistrum. In the cross with a French population, all offspring were hybrids; in the cross with a Swiss population, $53 \%$ of the offspring were hybrids; and in the cross with a Danish population, only $2 \%$ of the offspring were found to be hybrids. The remaining offspring apparently belonged to two groups: the majority was $B$. napus-like plants, possibly of matromorphic origin, and a minority from the Danish cross seemed to carry fragments of the Raphanus genome. In the cross with a cultivated $R$. sativus, all offspring were found to be hybrids. This is the first report on spontaneous hybridization between $B$. napus and $R$. sativus. Hybrids from all cross-combinations had low pollen fertility $(0-15 \%)$. If $R$. raphanistrum occurs where male-sterile $B$. napus is cultivated, large regional differences in hybridization frequencies between the species could complicate environmental risk assessment of transgenic oilseed rape.
\end{abstract}

Keywords: hybridization frequencies / population differences / ISSR / seed dimorphism

\section{INTRODUCTION}

One concern of growing transgenic oilseed rape is the risk of transgene flow from the genetically modified crop to wild or weedy relatives, and the consequences gene dispersal might have for wild populations and for their ability to create weed problems (Scheffler and Dale, 1994). For the overall estimation of the potential risks of cultivating genetically modified (GM) crops, the European Union has common risk-assessment guidelines (Directive 2001/18/ EC). The risk assessment procedure demands evaluation of gene flow from a genetically modified crop to wild recipients, and in this respect it is important that the variation in gene flow is known and not just assumed to be identical in all regions and for all genotypes. Therefore, we compared hybridization frequencies between a malesterile line of B. napus and three $R$. raphanistrum popu-

\footnotetext{
* Corresponding author: rikke.bagger.jorgensen@ risoe.dk
}

lations from different regions in Europe. Hybrids between $B$. napus and $R$. raphanistrum have been found to occur spontaneously (Baranger et al., 1995; Darmency et al., 1998; Eber et al., 1994; Rieger et al., 2001; Warwick et al., 2003), but spontaneous hybridization between $B$. napus and $R$. sativus has not been reported previously, and we therefore included $R$. sativus in our crossing experiment. A male-sterile line of B. napus was used as maternal line in the hybridizations, which is relevant as varietal associations with male-sterile B. napus are cultivated in Europe (Booth, 1998). Male-sterile plants could potentially have increased outcrossing, for instance with GM fields in the neighborhood. Also, hybrid varieties of oilseed rape may retain some male sterility that also enhances outcrossing (Eastham and Sweet, 2002). 
$R$. raphanistrum is self-incompatible (Sampson, 1964), and occurs as a weed in agricultural fields and as a ruderal plant on sandy soils (Chèvre et al., 2004; Tutin et al., 1980). Its seeds can remain viable in the soil for many years (Roberts and Boddrell, 1983), and it is an economically damaging weed worldwide (Holm et al., 1997). R. sativus is also self-incompatible (Karron et al., 1990), and cultivated in large areas of the world, where it can escape from cultivation and colonize disturbed sites such as roadsides, fields and coastal sand dunes (Snow et al., 2001). Overlap in flowering time between crop and weeds makes interspecific pollination events possible in Europe, since $R$. raphanistrum and $R$. sativus flower in early to late summer and $B$. napus in spring to early summer (winter oilseed rape) and early to mid summer (spring oilseed rape).

In the field, the frequency of spontaneous hybridization between $R$. raphanistrum and fertile lines of oilseed rape was found to be extremely low (Chèvre et al., 2000; Rieger et al., 2001; Thalmann et al., 2001; Warwick et al., 2003), as were frequencies of backcrosses to $R$. raphanistrum in field experiments (Chèvre et al., 1998). When male-sterile B. napus is pollinated by $R$. raphanistrum, hybridization frequencies increase (Baranger et al., 1995). Hybrids between B. napus and $R$. raphanistrum are vigorous and almost sterile (Lefol et al., 1997), but fertility increases in the following backcross generations (Chèvre et al., 1998). Some of the backcross plants with $R$. raphanus had chromosome numbers close to that of the wild parent, and retained B. napus markers and the transgene from the crop (Chèvre et al., 1998). However, these B. napus markers were apparently not stably recombined into the $R$. raphanistrum genome. As the transgene is retained, the hybrids $-F_{1}$ and wider hybrid generations - may potentially affect the environment in unwanted ways.

In the present study we set off to analyze if hybridization frequencies between oilseed rape and $R$. raphanistrum was influenced by populational differences. Our results are discussed in relation to environmental risk assessments of GM plants.

\section{RESULTS}

Table 1 shows the data obtained on seed set, seed size, seed weight, pollen fertility, the morphological categories, genetic marker analysis, and ploidy. For each crosscombination the results in Table 1 were obtained from the same sets of plants, although sample sizes vary among traits.

\section{Variation in seed size and seed set}

Within the four cross combinations, the 20 B. napus plants seemed to contribute almost equally to pod and seed set, and therefore seeds were harvested on a population basis. Seeds from the $R$. sativus cross and the cross with the French $R$. raphanistrum population had similar sizes, and both these crosses had 2-3 times fewer seed per pod than plants from the Danish cross and the Swiss cross. Seed morphology results from all crosses are shown in Figure 1. The seeds from the $R$. sativus and French crosses were all quite small $(0.8-1.5 \mathrm{~mm})$, whereas seeds from the Swiss cross fell into two groups, the larger group (68\%) was similar to the small-sized seeds from the $R$. sativus cross and the French cross $(0.8-1.5 \mathrm{~mm})$. The other group (32\%) consisted of larger seeds $(1.5-2.1 \mathrm{~mm})$. Seeds from the Danish cross also fell into these two size-groups; very few (9\%) were small $(0.8-1.5 \mathrm{~mm})$ whereas the majority (91\%) was larger $(1.5-2.1 \mathrm{~mm})$. The large seeds did not have the characteristic round and smooth morphology of normal B. napus seeds. Instead, these seeds were asymmetric, rough and each seed had its own characteristic shape (Fig. 1). The weight of 100 seeds was very similar in the French $R$. raphanistrum cross and the $R$. sativus cross $(p=0.944)$, and significantly less than in the other two crosses $(p<0.001)$, which also differed significantly from each other $(p<0.001)$.

\section{Morphology of the offspring plants}

There did not seem to be substantial differences in seed germination among crosses after the dormancy breaking treatment. Seeds of each seed size were grown in a separate experiment to evaluate the correlation between seed size and morphology of the offspring plants. This experiment showed that plants reared from small seeds had hybrid morphology and plants from large seeds had B. napus-like morphology.

The morphology of approximately 100 offspring plants per cross-combination is given in Table 1 . The offspring plants produced from the cross with the French population of $R$. raphanistrum, and those produced with $R$. sativus all looked like interspecific hybrids. Except for a few hybrid-looking plants, morphology of the offspring fathered by the Danish population of $R$. raphanistrum was B. napus-like. However, some of these had a few prickly hairs on the leaves and could not be morphologically categorized as either B. napus or as hybrids (19.6\% of the offspring from this cross, $\mathrm{NC}=$ non-categorized, see Tab. 1). Such deviating morphology was also found among the offspring plants from the cross with the Swiss 
Population-dependent hybridization

Table 1. Spontaneous crosses between male sterile B. napus (female) and accessions of Raphanus raphanistrum or Raphanus sativus: seed set, seed sizes, pollen fertility, morphological and genetic identification of offspring.

\begin{tabular}{|c|c|c|c|c|}
\hline \multicolumn{5}{|c|}{$\mathrm{F}_{1}$ offspring between B. napus and Raphanus } \\
\hline Male parent & $\begin{array}{c}\text { Swiss } \\
\text { population }\end{array}$ & $\begin{array}{c}\text { Danish } \\
\text { population }\end{array}$ & $\begin{array}{l}\text { French } \\
\text { population }\end{array}$ & $\begin{array}{c}\text { sativus } \\
\text { population }\end{array}$ \\
\hline \multicolumn{5}{|c|}{ Seed data } \\
\hline Pods (20 pl.) / per pl. & $1726 / 86.3$ & $662 / 33.1$ & $1548 / 77.4$ & $1739 / 87.0$ \\
\hline Seeds (20 pl.) / per pl. & $2021 / 101.1$ & $755 / 37.8$ & $541 / 27.1$ & $1065 / 53.3$ \\
\hline Seeds per pod & 1.17 & 1.14 & 0.35 & 0.61 \\
\hline Seed size, $\mathrm{mm}^{\mathrm{a}}$ & $\begin{array}{c}0.8<68 \%<1.5 \\
1.5<32 \%<2.1\end{array}$ & $\begin{array}{l}0.8<9 \%<1.5 \\
1.5<91 \%<2.1\end{array}$ & $0.8<100 \%<1.5$ & $0.8<100 \%<1.5$ \\
\hline Weight of 100 seed, g & $0.169 \pm 0.007$ & $0.346 \pm 0.010$ & $0.061 \pm 0.000$ & $0.064 \pm 0.003$ \\
\hline \multicolumn{5}{|c|}{ Morphological evaluation } \\
\hline Hybrids, \% (\# plants) & $57.4(54)$ & $4.3(4)$ & $100(100)$ & $100(100)$ \\
\hline B. napus-like, \% (\# pl.) & $31.9(30)$ & $76.1(70)$ & $0 \quad(0)$ & $0 \quad(0)$ \\
\hline $\mathrm{NC}, \%$ (\# pl.) & $10.6(10)$ & $19.6(18)$ & $0 \quad(0)$ & $0 \quad(0)$ \\
\hline Total, \% (\# pl.) & $100(94)$ & $100(92)$ & $100(100)$ & $100(100)$ \\
\hline \multicolumn{5}{|c|}{ Genetic analysis } \\
\hline Hybrids, \% (\# pl.) & $53.2(50)$ & $1.7(2)$ & $100.0\left(20^{\mathfrak{c}}\right)$ & $100.0\left(20^{\mathrm{c}}\right)$ \\
\hline B. napus-like, \% (\# pl.) & $44.7(42)$ & $75.0(90)$ & $0.0 \quad(0)$ & $0.0 \quad(0)$ \\
\hline $\mathrm{FRB}, \%$ (\# pl.) & $0.0 \quad(0)$ & $23.3(28)$ & $0.0 \quad(0)$ & $0.0 \quad(0)$ \\
\hline Total, \% (\# pl.) & $100.0(92)$ & $100.0(120)$ & $100.0(20)$ & $100.0(20)$ \\
\hline Seeds per pod that were hybrids ${ }^{b}$ & 0.62 & 0.02 & 0.35 & 0.61 \\
\hline \multicolumn{5}{|c|}{ Pollen fertility, $\%$} \\
\hline Parental plants & $87(7) \pm 27$ & $79(7) \pm 27$ & $74(6) \pm 30$ & $86(7) \pm 20$ \\
\hline Hybrids & $3(9) \pm 5$ & $\mathrm{nd}^{\mathrm{d}},(\mathrm{FRB}>90 \%(4))$ & $1(10) \pm 1$ & $6(9) \pm 5$ \\
\hline \multicolumn{5}{|c|}{ Chromosome number or ploidy level } \\
\hline Chromosome number, (\# pl.) & & $2 n=28(1), 2 n=38(4)$ & $2 n=28(3), 2 n=56(2)$ & \\
\hline Flow cytometry, (\# pl.) & triploid (1) & tetraploid (28) & & triploid (1) \\
\hline $\begin{array}{l}\text { The table shows the percentages (tl } \\
\text { categorized (NC), or as containing } \\
\text { a Distribution of the total amount o } \\
\text { b Based on the results of the ISSR } \\
{ }^{c} \text { As all } 100 \text { plants analysed morph } \\
\text { d The two } \text { F }_{1} \text { hybrids from the cross- } \\
\text { fertility impossible. }\end{array}$ & $\begin{array}{l}\text { ber of plants give } \\
\text { Raphanus Bands } \\
\text { within size cate } \\
\text { analysis. } \\
\text { ally were clearly } \\
\text { nation with the D }\end{array}$ & $\begin{array}{l}\text { brackets) of plants analy } \\
\text { B). } \\
\text { s defined by the seed dial } \\
\text { ids, only } 20 \text { of them unde } \\
\text { population inherited the } 1\end{array}$ & $\begin{array}{l}\text { d and classified as hyb } \\
\text { eter. } \\
\text { went ISSR analyses. } \\
\text { ale sterility trait, which } 1\end{array}$ & $\begin{array}{l}\text { as B. napus, as non- } \\
\text { estimation of pollen }\end{array}$ \\
\hline
\end{tabular}

population ( $10.6 \%$ of the offspring from this cross), whereas the remaining offspring from this cross was found to be either hybrid-like or B. napus-like plants (Tab. 1).

\section{Genetic marker analysis}

In the ISSR analysis, there was a clear distinction between the parental species B. napus and Raphanus (Fig. 2), as several markers were specific for one or the other species.
No variation was found within B. napus, as all markers were monomorphic in the 80 plants analyzed (randomly selected from the same seed sample as the maternal plants). Quite opposite, ISSR analysis of the three R. raphanistrum accessions displayed much intrapopulational variation in accordance with the outcrossing nature of this species; $R$. sativus was also quite variable. Raphanusspecific markers were easily found, but none of them were monomorphic over all four populations. As a consequence 


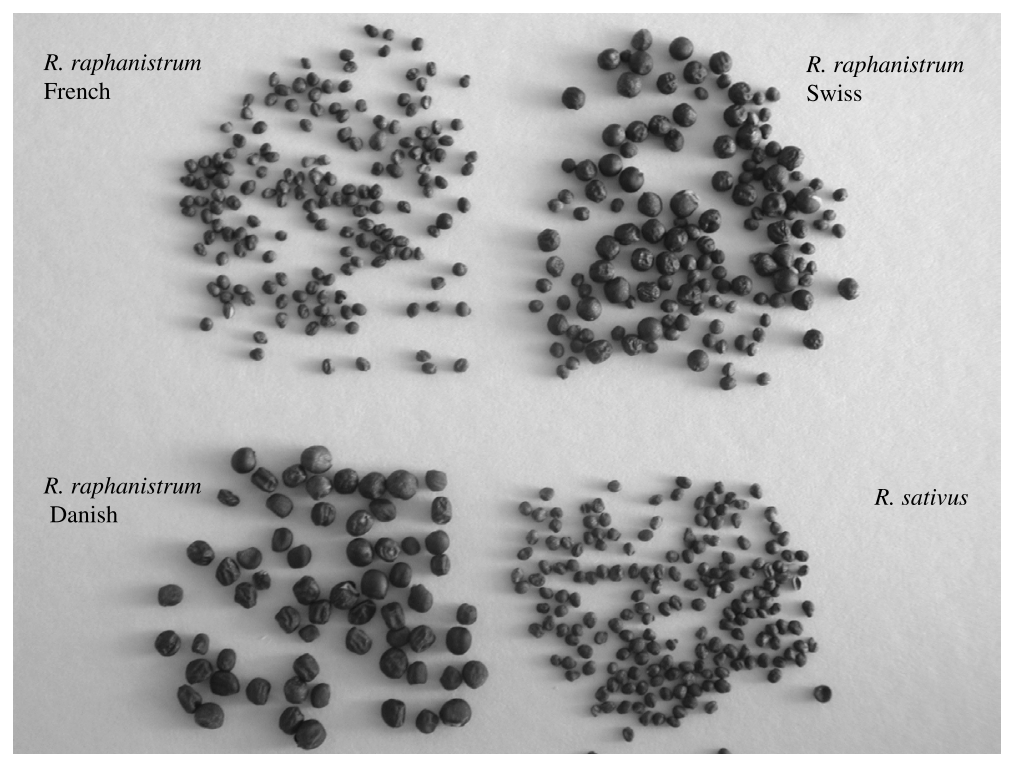

Figure 1. Size and shape dimorphism of seeds from crosses between male-sterile Brassica napus and one cultivar of Raphanus sativus and three different populations of Raphanus raphanistrum - a French, Swiss and Danish.
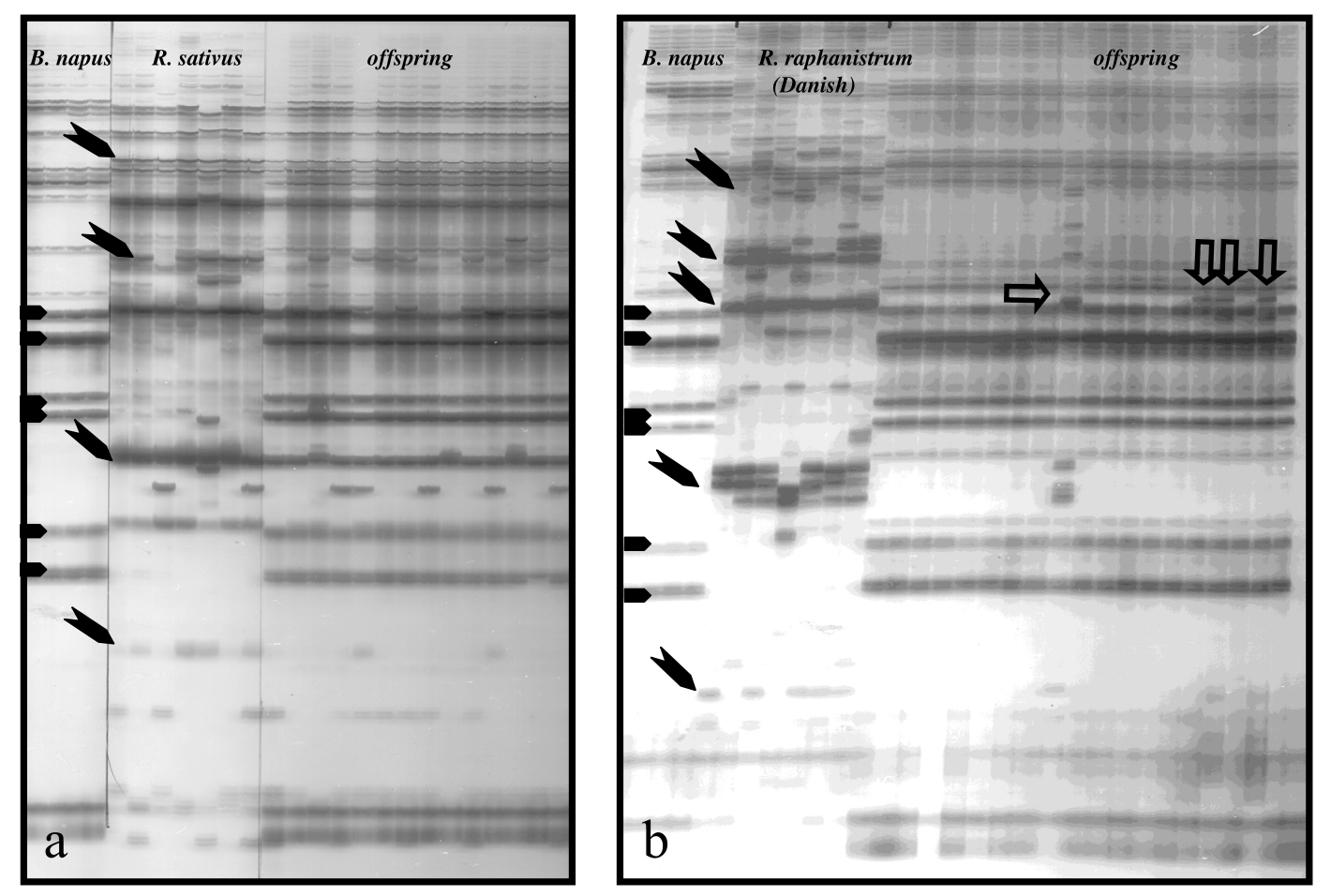

Figure 2. ISSR profiles of parents and offspring from the Brassica napus and Raphanus crosses; (a) cross with R. sativus; (b) cross with the Danish population of $R$. raphanistrum. Some of the gel zones with diagnostic Raphanus bands are given (long filled arrows), as are six B. napus bands, never observed in Raphanus (short filled arrows). All offspring in panel a are hybrids; the hybrid plant in panel $\mathrm{b}$ is indicated by the unfilled horizontal arrow, and three offspring plants revealing only some of the Raphanus bands (FRB plants) are shown by unfilled vertical arrows. 
of the genetic variability in Raphanus, different sets of population-specific markers were used for identification of the hybrids in the four crosses. All Raphanus individuals had 8-27 specific markers differentiating them from oilseed rape, and B. napus had a minimum of 9-12 specific markers depending on which of the Raphanus accessions that were used as pollinator. Some of these crop-specific bands were never seen in any of the four Raphanus populations (Fig. 2).

Within the different cross-combinations, the hybrids showed variation in the bands inherited from the Raphanus parent, suggesting that their paternal DNA originated from different individuals. As seen in Figure 2, the interspecific hybrids could easily be detected by the ISSR-markers, as all hybrids had many Raphanus markers. However, some offspring with B. napusmorphology from the combination with the Danish $R$. raphanistrum were difficult to place as being either hybrids or $B$. napus. These plants had only 1-3 recurrent Raphanus markers (Fig. 2: plants designated as FRB = few Raphanus bands), whereas two hybrids from this cross and hybrids from the other crosses always inherited 7-15 of the Raphanus markers. The estimated numbers of hybrid seeds per pod based on the marker analysis are shown in Table 1.

\section{Ploidy levels}

Chromosome numbers were counted in five offspring from each of the French and the Danish crosscombinations with $R$. raphanistrum, as these two crosses represented high-frequency hybridization and lowfrequency hybridization, respectively. In five hybridlooking offspring from the French cross, three plants had 28 chromosomes, corresponding to what would be expected for an $\mathrm{F}_{1}$ hybrid (genome $\mathrm{ACRr}$ ), and two plants had 56 chromosomes (genome AACCRrRr?). All five plants from the Danish population resembled B. napus; however, one plant produced no pods when selfed (individual plants shaken to promote pollination), while the others had a pod and seed production equivalent to $B$. napus. Four of these plants had 38 chromosomes, like $B$. napus, whereas the one plant not producing pods had 28 chromosomes.

Flow-cytometric analysis was performed on 30 plants that were also evaluated by ISSR markers and morphology. They were four FRB plants and 24 B. napuslike offspring from the Danish cross and two hybrid plants, one each from the $R$. sativus and the Swiss $R$. raphanistrum cross. All 28 offspring from the Danish cross were categorized as tetraploid, and the hybrids from the $R$. sativus and the Swiss $R$. raphanistrum cross were triploids.

\section{Pollen fertility}

As expected from the hemizygous nature of the malesterile B. napus parent, $48 \%$ of the offspring identified as hybrids (from genetic marker analyses) were male-sterile. The male-fertile offspring had a low pollen fertility: between $0 \%$ and $15 \%$ for the 28 hybrids plants tested, and $1-6 \%$ for the four offspring populations (Tab. 1). Pollen fertility of the FRB offspring plants from the cross with the Danish population was more than $90 \%$ (Tab. 1), and at flowering, these plants were morphologically like oilseed rape. For comparison the paternal pollen fertility is given in Table 1.

Female fertility of the offspring was not accessed.

\section{DISCUSSION}

\section{Size dimorphism of seeds}

In this study, first generation hybrids between male-sterile $B$. napus and three populations of $R$. raphanistrum and one cultivar of $R$. sativus were produced spontaneously. The resulting seeds showed size dimorphism. In the French $R$. raphanistrum cross and the $R$. sativus cross, where all offspring were found to be hybrids (based on genetic markers and morphological analyses), all the seeds produced were small $(<1.5 \mathrm{~mm})$. In the crosses with the Danish and Swiss $R$. raphanistrum populations, where only part of the offspring were hybrids and the remaining B. napus-like plants, the seeds grouped into small seeds $(<1.5 \mathrm{~mm})$ and large seeds $(>1.5 \mathrm{~mm})$. Such relationship between small seed size and hybrid identity has previously been described for crosses between male-sterile B. napus and $R$. raphanistrum (Baranger et al., 1995), and is also known from other Brassica crosses (Eenink, 1974 a, b; 1975). In contrast to the experiment by Baranger et al. (1995), our crosses were made in pollen-tight chambers with no fertile $B$. napus grown in the vicinity, and we therefore believe that the seedlings resembling B. napus could not derive from unintended pollination by $B$. napus pollen. This is supported by the fact that no B. napus-like plants were obtained from two of the crosses. Observations on size and shape dimorphism of seeds containing matromorphic plants (matromorphy development of unfertilized ovules) have previously been described in crosses between B. oleracea and related species (Eenink, 1975). Hence, the seeds producing $B$. napus-like plants might be matromorphs, produced 


\section{H. Ammitzbøll, R. Bagger Jørgensen}

asexually by the $B$. napus mother, possibly stimulated by the foreign pollen of $R$. raphanistrum. However, as the marker analysis revealed (see discussion of B. napus $\times R$. raphanistrum crosses), these seeds could also represent plants that were derived from hybrids that had lost most of the Raphanus genome.

\section{Fertility of the hybrids}

Pollen fertility of the hybrids was quite low (0-15\%), and in agreement with previous results from hybrids of $B$. napus $\times R$. raphanistrum crosses (Baranger et al., 1995; Chèvre et al., 1998; Chèvre et al., 2000). This implies that fertilization by the $F_{1}$ hybrids will be limited. The low male fertility is likely to slow down further introgression of transgenes, as is also suggested by the low frequency of spontaneous production of backcross plants; when $\mathrm{F}_{1}$ hybrids were pollinated by $R$. raphanistrum in the field, 0.78 seeds/plant were produced (Chèvre et al., 1998). However, the $\mathrm{F}_{1}$ hybrids - the first step in the introgression process - could themselves be problematic to the environment.

\section{Crosses}

\section{The $\mathrm{B}$. napus $\mathrm{x}$ R. sativus cross}

Hybrids between $B$. napus and $R$. sativus have previously been reported using embryo rescue (Lelivelt et al., 1993; Paulmann and Röbbelen, 1988; Takeshita et al., 1980). However, the present study demonstrates that hybridization between these species is indeed possible without hand pollination or embryo rescue, using malesterile B. napus.

The reason we obtained so many hybrids was likely due to the lack of competition from conspecific pollen on the $B$. napus stigma. Experiments on pollen competition in crosses between $B$. napus and $B$. rapa have shown that $B$. rapa pollen in B. napus styles had a significantly lower fitness than the conspecific pollen (Hauser et al., 1997). As fertile lines of $B$. napus are highly selfing, the likelihood of heterospecific pollen fertilizing a $B$. napus plant under field conditions is limited. However, varietal associations with a mix of male-sterile and -fertile $B$. napus plants are cultivated (Booth, 1998), and also hybrid varieties may have some male sterility (Eastham and Sweet, 2002). The chance of outcrossing in these situations is substantially increased, and hence also the chance of interspecific hybridization (Chèvre et al., 2000; Eastham and Sweet, 2002).
Spontaneous hybridization between $B$. napus and $R$. sativus has not been considered in the environmental risk assessment prior to release of transgenic B. napus, since it has not been known to occur. If it does take place in nature, this route of gene escape should also be considered when releasing GM oilseed rape, as $R$. sativus may occur as a feral or volunteer and hybridize readily with $R$. raphanistrum (Klinger et al., 1992; Snow et al., 2001; Warwick and Francis, 2005). Post-release monitoring might detect the occurrence of such hybrids in the future, but investigations of the frequency of interspecific hybridization under natural conditions seem necessary in order to include the likelihood of the event in pre-release risk assessment of a specific transgenic line (directive 2001/18/EC). Any possible environmental consequences of this hybridization then have to be considered.

\section{The B. napus $\mathrm{x}$. raphanistrum crosses}

The DNA marker analysis revealed that the French and Swiss crosses produced 18-30 times more hybrid seeds per pod than the Danish cross. This suggests a difference in hybridisation potential relating to the genotype of the $R$. raphanistrum population. Although chamber effects are possible, genetic differences in pollen source are the most likely explanation for the observed differences, as chambers were identical as to size, orientation etc., and only had natural light.

The ability of $R$. raphanistrum pollen to penetrate the micropyle and fertilize the ovule was analyzed for two oilseed rape varieties by Gueritaine et al. (2003). They observed variations between seven $R$. raphanistrum plants from a single population and suggested that the variation in fertilization frequency depended on the genotype of the wild $R$. raphanistrum parent (Gueritaine et al., 2003). Genotypic differences between plants within the populations could be the reason for our observed differences in hybridization frequencies, but in contrast to the experiment by Gueritaine et al. (2003), we used 20 plants from each of four different populations of Raphanus and studied the seed production and offspring generation. Within the four cross-combinations, the variation in the bands inherited from the Raphanus parent suggests that the paternal DNA originated from different individuals. Hence, our results on the ability to produce interspecific hybrids appear to relate to population differences rather than individual variations among plants.

Several explanations for the difference in hybridisation frequencies among $R$. raphanistrum populations are possible. One of them could be that the hybridization potential differs due to different levels of already existing 
introgression of $R$. sativus genes into the $R$. raphanistrum local population. Gene flow from $R$. sativus to $R$. raphanistrum is known to occur (Klinger et al., 1992; Snow et al., 2001). Since our results have shown a high frequency of hybridization with $R$. sativus, the presence of introgressed $R$. sativus genes in a population of $R$. raphanistrum might result in a higher ability to hybridize with B. napus, such as we found for the French population and the Swiss population in our experiment.

For the Swiss and Danish cross-combinations, the frequency of hybrids identified by morphology versus marker analysis was not quite identical. This discrepancy is probably due to that morphological scoring of hybrids at the 4-leaf stage is more uncertain than at later developmental stages, where pod production could reveal plant fertility/sterility. In conclusion, identifying $\mathrm{F}_{1}$ plants between $B$. napus and $R$. raphanistrum cannot be done reliably using morphology alone.

\section{Odd cytotypes and offspring with few Raphanus bands}

In the Danish cross, $23.3 \%$ of the offspring plants could not be classified as either hybrids or matromorphs, due to the occurrence of a few Raphanus specific bands in an otherwise B. napus genetic fingerprint $(\mathrm{FRB}=$ few Raphanus bands, Fig. 2). The bands could be linked, as it was always the same 1-3 bands that were inherited. Repetition of the ISSR analysis confirmed the presence and high frequency of FRB in the offspring from this cross. Our results from ISSR analysis of the B. napus variety showed that the bands did not originate from the genetically homogeneous $B$. napus variety.

In a field experiment, Warwick et al. (2003) found a spontaneous hybrid between $R$. raphanistrum and $B$. napus. This hybrid probably had the genome constitution $\operatorname{RrRrAC}(2 n=37)$, and originated from fertilization of an unreduced Raphanus female gamete. This plant had morphology similar to $R$. raphanistrum, and its pollen fertility was very low $(0.12 \%)$. The four FRB plants analysed by flow-cytometry were apparently tetraploid (or had a chromosome number close to the tetraploid number), their pollen fertility was normal (>90\%) and their morphology B. napus-like. Therefore, in contrast to the hybrid found by Warwick et al. (2003), the FRB plants most likely contained only a small amount of DNA from $R$. raphanistrum.

One explanation of the presence of FRB is that the bands are pollen-borne cytoplasmic DNA. Plant genera displaying some degree of biparental cytoplasmic DNA inheritance has been found in some taxa (e.g., Mogensen, 1996). Reciprocal crosses between B. napus and R. raphanistrum could reveal a possible paternal cytoplasmic inheritance between these species. Johannessen et al. (2005) found the chance of paternal inheritance of cytoplasmic DNA in reciprocal crosses between $B$. napus and $B$. rapa - another weedy relative of B. napus - to be less than 0.015. Another possibility is that the FRB plants developed from interspecific hybrids that lost most of the Raphanus genome by chromosome elimination early in their embryo or seedling stage, combined with a doubling of the genome. Genome doubling and chromosome elimination has been suggested to occur in interspecific hybridizations between B. napus and Orychophragmus violaceus (Cheng et al., 2002). If the FRB plants developed from a process involving elimination and genome doubling, then the B. napus-like plants assumed to be matromorphic might also have developed from a hybridization event, but here elimination of the Raphanus genome was more complete or at least not evident with the present set of ISSR markers. If the FRB plants carry just a small fragment of the genome from the father, hybridization may be difficult to detect. Investigations of the possible chromosome elimination involved in the production of the B. napus-like plants will be the aim of a separate study. If the majority of B. napus-like plants developed as true matromorphs without preceding hybridization and chromosome elimination, then the differences between the Danish and the Swiss populations may relate to the ability to produce such matromorphs.

\section{Conclusions}

To summarize, using morphological and ISSR analysis we observed large differences in the frequencies of hybrids from crosses between oilseed rape and three populations of the weedy relative $R$. raphanistrum. As a consequence of this population-dependent hybridization frequency, introgression of oilseed rape genes to wild recipients is likely to take place with different speed in different regions. In the future, more studies with free pollen competition under natural conditions are needed to confirm the existence of the regional differences in hybridization found in the greenhouse. If large population differences exist in hybridization frequency, this should be considered when making predictions about the level of risk when growing transgenic B. napus. However, it is important to remember that even if spontaneous hybridization with oilseed rape is frequent for some Raphanus populations, further introgression of the 
transgene will probably be slowed, due to reduced hybrid fertility (Chèvre et al., 1998). Also, the fact that B. napus hybridized readily with $R$. sativus in the present experiment ought to be investigated in more detail by evaluating frequencies of hybridization and spontaneous gene transfer in different combinations between B. napus and a range of $R$. sativus cultivars.

Hybridization followed by chromosome elimination and genome doubling are the most likely events that resulted in the offspring plants with few Raphanus bands (FRB). The finding of FRB plants suggests that hybridization events between $B$. napus and $R$. raphanistrum may occur more often than previously expected. If so, new considerations on the likelihood of transgene spread will have to be included in the risk assessment of growing transgenic oilseed rape.

\section{MATERIALS AND METHODS}

\section{Plant material}

A transgenic nuclear male-sterile $B$. napus ssp. oleifera (DC.) $(2 n=38$, AACC $)$ of the variety Drakkar was used as maternal parent in all crosses (provided by Plant Genetic Systems, Belgium). The plants express a transgenic tapetum specific ribonuclease (barnase) that completely prevents pollen development (Mariani et al., 1990). The trait is hemizygous and inherited in a Mendelian manner. This line was one of the first transgenic oilseed rape lines to be approved by EU (GMOaut, 2004), and it seems to be stable both as to inheritance and gene expression (Ammitzbøll et al., 2005).

Three different populations of $R$. raphanistrum (L.) $(2 n=18, \mathrm{RrRr})$ and one cultivar of $R$. sativus $(\mathrm{L}).(2 n=18$, $\mathrm{RR})$ were used as pollinators. The seeds of the $R$. raphanistrum populations were from a Danish population collected at northwest Zealand, a French population from Bretagne (kindly provided by A. Chèvre, Institut National de la Recherche Agronomique, Rennes), and a Swiss population (from near Zurich; kindly provided by M. Meier, Swiss Federal Institute of Technology, Zurich). The $R$. raphanistrum populations seemed morphologically very alike (but morphometric analysis was not performed); the most obvious difference being flower color: the plants germinated from the Danish and French populations had yellow flowers, while individuals from the Swiss population had white flowers. The $R$. sativus seeds were produced by the seed company Hammenhögs (Weibull Trädgård $\mathrm{AB}$, 27650 Hammenhög, Sweden). The variety was Flamboyant 3 .

\section{Spontaneous crosses}

The crosses took place during May in four separate pollentight chambers in a greenhouse with a constant temperature at $20{ }^{\circ} \mathrm{C}$ and no artificial light. In each chamber, 20 male-sterile B. napus plants were placed randomly between 20 plants of the specific $R$. raphanistrum or $R$. sativus population. Captive bumblebees, reared on artificial feed in mini-bee-hives, pollinated the plants for four weeks, while both B. napus and the Raphanus species were flowering. Bee activity seemed to be similar in the four chambers. Bees were replaced with new hives after two weeks, to ensure high pollination activity and no bees were allowed to move between chambers.

\section{Seed germination and seed size}

The pods formed on B. napus were harvested and their number determined per population (see Tab. 1). Offspring seeds were weighed in groups of 100 seeds, and the seed number (weight of all seeds/average weight 100 seeds) and seeds per pod were determined. Seed sizes were quantified by sorting the seeds through 11 sieves with circular holes of different diameters ranging from 0.5 $2.3 \mathrm{~mm}(0.5,0.75,0.8,1,1.25,1.5,1.75,1.85,2,2.1$ and $2.3 \mathrm{~mm}$ ). To visualize any connection between seed size and hybrid morphology of the emerging seedlings, an extra batch of seeds was sown: 14-30 small seeds $(<1.5 \mathrm{~mm})$ and 30 (where possible) large seeds $(>1.5 \mathrm{~mm})$ from each cross. Plants were grown to maturity.

From each cross-combination, randomly selected offspring seeds were sown together with 50 parental Raphanus seeds. For morphological comparison, 50 seeds from the mother line of B. napus (male-sterile var. Drakkar) were also sown. All seeds germinated in $40 \times$ $60 \mathrm{~cm}$ soil-trays. The trays were placed in a growth chamber, and a dormancy breaking temperature cycling was applied $\left(30^{\circ} \mathrm{C} /\right.$ light $9 \mathrm{~h}, 20^{\circ} \mathrm{C} /$ light $7 \mathrm{~h}$ and $17^{\circ} \mathrm{C} /$ darkness $8 \mathrm{~h}$ ). The temperature cycle was repeated for $96 \mathrm{~h}$.

\section{Morphological analysis}

At the 4-leaf stage 100 emerging offspring plants from each cross (see Tab. 1), and from the seed batches separated according to size, were classified as being hybrid-like or B. napus-like. Two types of offspring plants were identified - hybrid-like with intermediate traits between $R$. raphanistrum and $R$. sativus, with more lobed 
leaves, with prickled hairs and leaves without a visible wax layer, and B. napus-like plants that had less lobed leaves without prickled hairs but with a grayish wax layer. A third group of offspring that were not easily assigned to one of these two categories were designated as "noncategorized". Two people independently scored the morphology of the seedlings and obtained identical results.

\section{Genetic marker analysis}

Genetic marker analysis was applied on offspring from crosses, to analyze to what extent morphological classifications of the offspring as hybrids/non-hybrids were correct. At the 4-leaf stage, a $2-\mathrm{cm}^{2}$ piece of each leaf was collected from individual plants and frozen. DNA was extracted by taking the samples directly from liquid nitrogen, and macerating them in a mixer mill together with two steel beads. Thereafter the DNA was extracted using the CTAB-method modified by Steward and Via (1993) from Doyle and Doyle (1990). We used dominant ISSR markers (Inter Simple Sequence Repeats) according to the method described by Charters et al. (1996). Markers were scored as present or absent. The primers used were $\mathrm{BDB}-(\mathrm{CA})_{7}$.

For identification of species-specific markers, individuals from the parental accessions were screened: 80 individuals from the oilseed rape parent and 60 Raphanus individuals, 15 plants from each of the four Raphanus types. Subsequently, offspring plants were analyzed for the presence of ISSR markers. As all offspring from the French cross and the $R$. sativus cross had clear hybrid morphology and were very uniform, only 20 plants from each of these crosses were analyzed with molecular markers. As the offspring from the Danish and Swiss crosses had both hybrid-like and B. napus-like morphotypes, approximately 100 offspring from each of these morphologically characterized offspring populations were analyzed, plus 28 additional plants from the Danish cross that were also subjected to flow-cytometry. Offspring from the cross with the Danish populations were run twice to confirm reproducibility.

\section{Chromosome counts and flow-cytometry}

Chromosome numbers were counted in five offspring plants from each of the Danish and the French population crosses. Root tips were pre-treated in a $0.05 \%$ colchicine solution for two hours. The root tips were stained with Feulgen and squashed in $45 \%$ acetic acid. Chromosomes in three cells from each plant were counted.
Using flow-cytometry, ploidy level was determined for 30 offspring plants that were characterized by genetic markers and morphology (for plant identity, see Results): 28 plants from the Danish cross, one from each of the Swiss and the $R$. sativus crosses. As standards, the ploidy levels in three parental B. napus (tetraploid) and four parental Danish $R$. raphanistrum plants (diploid) were used. Three leaves were collected from each plant and sent to DLF Trifolium, Research Division, Højerupvej 31, DK4660 Store Heddinge that performed the flow-cytometry analysis. Fresh leaf material $\left(0.5 \mathrm{~cm}^{2}\right)$ was extracted and stained using the CyStain UV Presice P Kit (Partec, Münster). Samples were filtered though $50 \mu \mathrm{m}$ pore-size nylon filters (Partec CellTrics, Partec, Münster) and incubated at room temperature for $5 \mathrm{~min}$. A Partec PA Flow cytometer was used for the analysis.

\section{Pollen viability}

To determine the pollen viability, anthers from two flowers of each plant were collected and stained with cotton blue. The percentage of viable pollen grains was determined by finding the ratio of viable to non-viable pollen from 200 pollen grains per flower. Pollen viability was analyzed in flowers from 9-10 hybrids (confirmed by ISSR analysis) of each of the Swiss, French and $R$. sativus crossing combinations; in total 28 hybrids. From the Danish cross, the two hybrids found and the four FRB plants (few Raphanus bands, see results for a definition) exposed to flow-cytometry were analyzed. For comparison, flowers from 6-7 plants of each of the four paternal types were collected and pollen viability was determined.

\section{Statistical analysis}

Statistical analyses were made using the statistical software package SPSS for Windows (version 11.5; SPSS Inc., Chicago, USA). The significant level used was $\alpha=$ 0.05 . Differences in seed weights were analyzed using Univariate Analysis of Variance, including a Post Hoc Tukey B test. Differences in the number of hybrid offspring based on the results from the genetic marker analysis were analyzed by a Chi-Square test.

\section{ACKNOWLEDGEMENTS}

Bente Andersen is acknowledged for her technical assistance and Marina Johannessen for assistance with the ISSR technique. We also wish to acknowledge Plant Genetic Systems, Anne-Marie Chèvre and Mathias Meier for providing $B$. napus and $R$. raphanistrum seeds. 
We thank the Danish Research Agency (Centre of Bioethics and Risk assessment) and the EU project SIGMEA for funding this study.

Received May 4, 2005; accepted April 8, 2006.

\section{REFERENCES}

Ammitzbøll HA, Mikkelsen T, Jørgensen RB (2005) Environmental effects of transgene expression on hybrid fitness - a case study on oilseed rape. Environ. Biosafety Res. 4: $3-12$

Baranger A, Chèvre AM, Eber F, Renard M (1995) Effect of oilseed rape genotype on the spontaneous hybridisation rate with a weedy species: an assessment of transgene dispersal. Theor. Appl. Genet. 91: 956-963

Booth E (1998) Oilseed rape varieties for the millennium. Agronomy Roadshow 1998. http://www.hgca.com/ publications/documents/cropresearch/RD_roadshow_1998_ paper_3.pdf (accessed 06.11.2004)

Charters YM, Robertson A, Wilkinson MJ, Ramsay G (1996) PCR analysis of oilseed rape cultivars (Brassica napus L ssp oleifera) using 5'-anchored simple sequence repeat (SSR) primers. Theor. Appl. Genet. 92: 442-447

Cheng BF, Séguin-Swartz G, Somers DJ (2002) Cytogenetic and molecular characterization of intergeneric hybrids between Brassica napus and Orychophragmus violaceus. Genome 45: 110-115

Chèvre AM, Eber F, Baranger A, Hureau G, Barret P, Picault H, Renard M (1998) Characterization of backcross generations obtained under field conditions from oilseed rape-wild radish $F_{1}$ interspecific hybrids: an assessment of transgene dispersal. Theor. Appl. Genet. 97: 90-98

Chèvre AM, Eber F, Darmency $H$, Fleury A, Picault H, Letanneur JC, Renard M (2000) Assessment of interspecific hybridisation between transgenic oilseed rape and wild radish under normal agronomic conditions. Theor. Appl. Genet. 100: 1233-1239

Chèvre AM, Ammitzbøll H, Breckling B, Dietz-Pfeilstetter A, Eber F, Fargue A, César Gomez-Campo C, Jenczewski E, Jørgensen RB, Lavigne C, Meier MS, den Nijs H, Pascher K, Seguin-Swartz G, Sweet J, Stewart Jr. N, Warwick S (2004) A review on interspecific gene flow from oilseed rape to wild relatives. In: den Nijs HCM, Bartsch D, Sweet J, eds, Introgression from genetically modified plants into wild relatives, CABI publishing, pp 235-251

Darmency H, Lefol E, Fleury A (1998) Spontaneous hybridizations between oilseed rape and wild radish. Mol. Ecol. 7: 1467-1473

Directive 2001/18/EC of the European parliament and of the council, of 12 March 2001 http://europa.eu.int/eur-lex/pri/ en/oj/dat/2001/1_106/1_10620010417en00010038.pdf (accessed 1.06.2004)

Doyle JJ, Doyle JI (1990) Isolation of plant DNA from fresh tissue. Focus 12: 3-4
Eastham K, Sweet J (2002) Genetically modified organisms (GMOs): The significance of gene flow through pollen transfer. Environmental issue report no. 28, European Environment Agency, Copenhagen.

Eber F, Tanguy X, Chèvre AM, Baranger A, Vallée $\mathbf{P}$, Renard M (1994) Spontaneous hybridization between a male-sterile oilseed rape and two weeds. Theor. Appl. Genet. 88: $362-368$

Eenink AH (1974a) Matromorphy in Brassica oleracea L. I. Terminology, parthenogenesis in cruciferae and the formation and usability of matromorphic plants. Euphytica 23: 429-433

Eenink AH (1974b) Matromorphy in Brassica oleracea L. II. Differences in parthenogenetic ability and parthenogenesis inducing ability. Euphytica 23: 435-445

Eenink AH (1975) Matromorphy in Brassica oleracea L. VI. Research on ovules, embryos and endosperms after prickle pollinations. Euphytica 24: 33-43

GMOaut (2004) (GMOs authorised for feed use in the European Union in accordance with directives 90/220/EEC and 2001/18/EC) http://europa.eu.int/comm/food/food/ biotechnology/authorisation/feed_authorised.pdf (accessed 30.09.2004)

Gueritaine G, Bonavent JF, Darmency H (2003) Variation of prezygotic barriers in the interspecific hybridization between oilseed rape and wild radish. Euphytica 130: 349-353

Hauser TP, Jørgensen RB, Østergård H (1997) Preferential exclusion of hybrids in mixed pollinations between oilseed rape (Brassica napus) and weedy $B$. campestris (Brassicaceae). Am. J. Bot. 84: 756-762

Holm LG, Doll J, Holm E, Phancho J, Herberger J (1997) World weeds: natural histories and distributions. John Wiley and Sons, New York, USA

Johannessen MM, Andersen BA, Damgaard C, Jørgensen RB (2005) Maternal inheritance of chloroplasts between Brassica rapa and $\mathrm{F}_{1}$-hybrids demonstrated by cpDNA markers specific to oilseed rape and B. rapa. Mol. Breeding 16: $271-278$

Karron JD, Marshall DL, Oliveras DM (1990) Numbers of sporophytic self-incompatibility alleles in populations of wild radish. Theor. Appl. Genet. 79: 457-460

Klinger T, Arriola PE, Ellstrand N (1992) Crop-weed hybridisation in radish (Raphanus sativus); effects of distance and population size. Am. J. Bot. 79: 1431-1435

Lefol E, Sèguin-Swartz G, Downey RK (1997) Sexual hybridisation in crosses of cultivated Brassica species with the crucifers Erucastrum gallicum and Raphanus raphanistrum: Potential for gene introgression. Euphytica 95:127-139

Lelivelt CLC, Lange W, Dolstra O (1993) Intergeneric crosses for the transfer of resistance to the beet cyst nematode from Raphanus sativus to Brassica napus. Euphytica 68: $111-120$

Mariani C, DeBeukeleer M, DeBlock N, Goldberg RD (1990) Introduction of male sterility into plants by a chimaeric ribonuclease gene. Nature 347: 737-741 
Population-dependent hybridization

Mogensen HL (1996) The hows and whys of cytoplasmic inheritance in seed plants. Am. J. Bot. 83: 383-404

Paulmann W, Röbbelen G (1988) Effective transfer of cytoplasmic male sterility from radish (Raphanus sativus L.) to rape (Brassica napus L.). Plant Breeding 100: 299309

Rieger MA, Potter TD, Preston C, Powles SB (2001) Hybridisation between Brassica napus L. and Raphanus raphanistrum L. under agronomic field conditions. Theor. Appl. Genet. 103: 555-560

Roberts HA, Boddrell JE (1983) Seed survival and periodicity of seedling emergence in 8 species of cruciferae. Ann. Appl. Biol. 103: 301-304

Sampson DR (1964) A one-locus self-incompatibility system in Raphanus raphanistrum. Can. J. Genet. Cytol. 6: 435445

Scheffler JA, Dale PJ (1994) Opportunities for gene transfer from transgenic oilseed rape (Brassica napus) to related species. Transgenic Res. 3: 263-278

Snow AA, Uthus KL, Culley TM (2001) Fitness of hybrids between weedy and cultivated radish: implications for weed evolution. Ecol. Appl. 11: 934-949
Steward CN, Via LE (1993) A rapid CTAB DNA isolation technique useful for rapid fingerprinting and other applications. Biotechniques 14: 748

Takeshita M, Kato M, Tokumasu S (1980) Application of ovule culture to the production of intergeneric or interspecific hybrids in Brassica and Raphanus. Jpn. J. Genet. 55: 373-387

Thalmann C, Guadagnuolo R, Felber F (2001) Search for spontaneous hybridization between oilseed rape (Brassica napus L.) and wild radish (Raphanus raphanistrum L.) in agricultural zones and evaluation of the genetic diversity of the wild species. Botanica Helvetica 111: 107-119

Tutin TG, Heywood VH, Burges NA, Valentine DH, Walters SM, Webb DA, eds (1980) Flora Europea. Cambridge University Press.

Warwick SI, Francis A (2005) The biology of Canadian weeds. 132. Raphanus raphanistrum. L. Can. J. Plant Sci. 85: 709-733

Warwick SI, Simard MJ, Légère A, Beckie HJ, Braun L, Zhu B, Mason P, Séguin-Swartz G, Stewart CN (2003) Hybridisation between transgenic Brassica napus L. And its wild relatives: Brassica rapa L., Raphanus raphanistrum L., Sinapis arvensis L., and Erucastrum gallicum (Wild.) O.E. Schulz. Theor. Appl. Genet. 107: 528-539
To access this journal online: www.edpsciences.org 